\title{
Investigating the Equilibrium Solubility of Carbon Dioxide in the Mixture of Triethanolamine, Piperazine and Water by Using CPA Equation of State
}

\author{
hossein ali dastan ${ }^{1}$, zahra sedghamiz ${ }^{1}$, Fereshteh Samadi ${ }^{1}$, and Ehsan Javadi Shokroo ${ }^{2}$ \\ ${ }^{1}$ Islamic Azad University Shiraz \\ ${ }^{2}$ FAPKCO Engineering Group
}

May 5, 2020

\begin{abstract}
In this study, the $\mathrm{CO} 2$ gas absorption process has been investigated modeling in order to find suitable adsorbent, as well as determination of the solubility and mass transfer mechanism. To calculate the solubility of $\mathrm{CO} 2$ in a solution of triethanolamine and piperazine, the CPA state equation will be used to predict the properties of the system. The results show that with increasing pressure, the absorption of $\mathrm{Co} 2$ in the gas phase increases due to the increase of the $\mathrm{CO} 2$ absorption of density gradient. By increasing the temperature, the amount of $\mathrm{CO} 2$ absorbed in the adsorbent solution decreases, due to the calorific of the Co2 absorption by the use of an amine absorbent solution. Also, by increasing the concentration of piperazine in the amine absorbent solution, the amount of $\mathrm{CO} 2$ absorption increases as a result of increasing the reaction rate of the amine solution with $\mathrm{CO} 2$ in the presence of piperazine. The highest overall error rate obtained from the reported data for operating pressure, temperature and piperazine concentrations variable is $7.3 \%, 7.4 \%$ and $4 \%$, which is considered an acceptable error rate, respectively.
\end{abstract}

\section{Hosted file}

Manuscript-All.docx available at https://authorea.com/users/293697/articles/421770investigating-the-equilibrium-solubility-of-carbon-dioxide-in-the-mixture-of-

triethanolamine-piperazine-and-water-by-using-cpa-equation-of-state 